\title{
Possible teleconnections between East and South Asian summer monsoon precipitation in projected future climate change
}

\author{
Sumin Woo ${ }^{1} \cdot$ Gyan Prakash Singh ${ }^{2} \cdot J_{a i-H o} \mathrm{Oh}^{1}$ (1) $\cdot$ Kyoung-Min Lee ${ }^{3}$
}

Received: 31 August 2017 / Accepted: 8 December 2017 / Published online: 6 January 2018

(c) The Author(s) 2018. This article is an open access publication

\begin{abstract}
The present paper examined the teleconnections between two huge Asian summer monsoon components (South and East Asia) during three time slices in future: near-(2010-2039), mid-(2040-2069) and far-(2070-2100) futures under the RCP4.5 and RCP8.5 scenarios. For this purpose, a high-resolution atmospheric general circulation model is used and integrated at $40 \mathrm{~km}$ horizontal resolution. To get more insight into the relationships between the two Asian monsoon components, we have studied the spatial displaying correlation coefficients (CCs) pattern of precipitation over the entire Asian monsoon region with that of South Asia and three regions of East Asia (North China, Korea-Japan and Southern China) separately during the same three time slices. The possible factors responsible for these teleconnections are explored by using mean sea level pressure (MSLP) and wind fields at $850 \mathrm{hPa}$. The CC pattern of precipitation over South Asia shows an in-phase relationship with North China and an out-of-phase relationship with Korea-Japan, while precipitation variations over Korea-Japan and Southern China exhibit an out-of-phase relationship with South Asia. The CCs analysis between the two Asian blocks during different time slices shows the strongest CCs during the near and far future with the RCP8.5 scenario. The CC pattern of precipitation over Korea-Japan and Southern China with the wind (at $850 \mathrm{hPa}$ ) and MSLP fields indicate that the major parts of the moisture over Korea-Japan gets transported from the west Pacific along the western limb of NPSH, while the moisture over Southern China comes from the Bay of Bengal and South China Seas for good monsoon activity.
\end{abstract}

\section{Introduction}

The East Asian and Indian Summer Monsoons (EASM and ISM) are two important components of the huge Asian summer monsoon system; however, these two components are largely associated with the different circulation systems that have been reviewed in many studies (Ramage 1971; Wang 2006; Preethi et al. 2017a; Wu 2017). The ISM is influenced by the low-level cross-equatorial flow over the tropical Indian Ocean and is largely controlled by semi-permanent

Responsible Editor: A.-P. Dimri.

Jai-Ho Oh

jhoh@pknu.ac.kr

1 Department of Environmental and Atmospheric Sciences, Pukyong National University, 45, Yongso-ro, Nam-gu, Busan 48513, South Korea

2 Department of Geophysics, Institute of Science, Banaras Hindu University, Varanasi 221005, India

3 CRAY Korea Inc., \#317, 24, Seochojungang-ro, Seocho-Gu, Seoul 06601, South Korea features such as heat low over northwest India, the upper level tropical easterly jet over the Indian Ocean, Mascarene High, and anticyclonic circulation over the Tibetan Plateau (Lau et al. 2000; Sarthi et al. 2012), whereas the EASM is more complicated due to the mixed effect of both southwesterly and southeasterly flows from Indo-Pacific Ocean. Hence, it is influenced by the south-westerlies from the extended tropical Indian Ocean as well as the anticyclonic circulation over the Western Pacific known as North Pacific Subtropical High (NPSH) and their complex interactions lead to the large precipitation variabilities over the monsoon rainband (Mei-yu/Changma/Baiu) (Tao and Chen 1987; Lau et al. 2000; Wang et al. 2001; Sarthi et al. 2012).

The summer precipitation over South (India) and East Asia shows large temporal variabilities ranging from subseasonal to multi-decadal timescales (Krishnamurti and Bhalme 1976; Yasunari 1980; Gadgil 2003; Ding and Chan 2005; Goswami 2005). Some of the studies have well described the epochal variations of summer precipitation over South and East Asia (Kripalani and Kulkarni 2001; Josepth et al. 2016). They have found a clear trend in precipitation and it well describes the statistical relationship 
between the two Asian monsoon components. The epochal characteristics of summer precipitation over South Asia depicted an alternate epoch of below normal, followed by three decades of above normal precipitation. Similarly, over East Asia, similar epochal changes as noticed over South Asia are found over North China, except a decadal lag to that of India. However, over Japan, epochs tend to lose approximately after five decades compared to South Asia (Kripalani and Kulkarni 2001). The characteristics of epochal changes in seasonal precipitation indicate that there could be some teleconnection between South and East Asian monsoon components on different timescales ranging from sub-seasonal to multi-decadal scales. It can also be possible that the teleconnections between the two Asian monsoon components behave differently on different timescales. For example, some periods have shown strong connection and others show weak connection or even no connections. This requires a further detailed analysis.

The relationships between the observed summer monsoon precipitations over South and East Asian regions have been reviewed in many studies (Kripalani and Kulkarni 1997, 2001; Krishnan and Sugi 2001; Wang et al. 2001; Wu and Wang 2002). Typically, an out-of-phase connection has been detected between EASM and ISM. For their subregions, an in-phase relationship between India and North China summer has been reported in Kripalani and Singh (1993) and Kripalani and Kulkarni (2001). However, an out-of-phase relationship has been observed between Indian summer rainfall and rainfall variation from Northeast India up to Southern China-South Korea-Southern Japan (Kripalani and Kulkarni 1997, 2001; Krishnan and Sugi 2001; Kim et al. 2002). As known, the precipitation is one of the important elements of the rainy season over the Asian continent, and from June to September it is the highest amount as compared to the rainfall during the rest of the months of a year. Another important fact about summer precipitation is its larger interannual variability that is of great concern to the large societal and economic consequences on the Asian countries. There are numerous studies on the teleconnection between South and East Asian monsoon mostly for the present-day climate condition based on the observed datasets. But it is very important to know the nature of these relationships in future, which can help in long-term government policies.

Some studies have mentioned large changes in Asian monsoon precipitation like an increase over East Asia and a decrease over South Asia during the last several decades (Kripalani et al. 2002; Yun et al. 2014; Preethi et al. 2017b) in the backdrop of global warming. Some studies have explored the probable future changes in Asian monsoon precipitation using coupled model intercomparison project phase 5 (CMIP5; Taylor et al. 2012) simulated datasets and found a large diversity among the models with large biases.
For example, Josepth et al. (2016) reported a dry epoch over South Asia during 2040-2069 based on CMIP5 model output datasets. But the non-stationarity of longer periodicity (Goswami 2005) and secular variations in monsoon teleconnections between the two Asian monsoon components (Kripalani and Kulkarni 1997) make it uncertain about the future characteristics of trend and teleconnections. Some models are able of capturing the correct sign of the relationship between South and East Asian seasonal summer monsoon precipitation, an in-phase relationship with the North China and out-of-phase correlationships with Korea-Japan. This suggests that the numerical models can be used for the detailed study of the future behavior of teleconnection and understand the processes involved in connecting the two Asian monsoon systems.

The present study is therefore aimed at investigating the possible relationship between South (Indian monsoon) and East Asian monsoon precipitation in near, mid and far future using a high-resolution atmospheric general circulation model (GME) at the $40 \mathrm{~km}$ horizontal resolution under two RCP (RCP4.5 and RCP8.5) scenarios. Section 2 presents the details of the model and experimental design, while detailed descriptions of the relationships between the two Asian blocks during the present-day climate conditions are presented in Sect. 3 and possible future projected trend and teleconnections are described in Sect. 4 and Sect. 5, respectively. Finally, the conclusion is given in Sect. 6.

\section{Description of the GME model, observed data and simulation details}

\subsection{GME model}

The GME (AGCM) used here is an operational global numerical weather prediction (NWP) model of German Weather services (Majewski et al. 2002). The GME works on uniform icosahedral-hexagonal grids. This method provides two advantages: firstly, it avoids the pole problem in latitude-longitude grids, which is a major drawback of the spectral technique. Secondly, it provides the data structure which is well suited and enhances the efficiency of distributed memory parallel computers. The mass flux convection scheme was used for the cumulus parameterization (Tiedtke 1989). For long-term simulation, the mass correction was applied in the GME model (Chaudhari 2006). In this study, GME has been run at very high resolution $\left(n_{\mathrm{i}}=192\right.$, L40) such as $40 \mathrm{~km}$ corresponding to $T_{L} 511$ of ECMWF, where $n_{i}$ is the number of equal intervals into which each side of the original icosahedral triangles is divided. In $\mathrm{n}_{\mathrm{i}} 192(40-\mathrm{km}$ mesh size), the number of grid points is 368,642 and transform grid uses $900 \times 451$ grid cells. GME has 40 levels in 
the vertical with a model top at $10 \mathrm{hPa}$. Detailed descriptions of the GME experiment are summarized in Table 1.

\subsection{Experiment design}

With GME, we conducted two types of model simulations: (a) present-day climate for testing the model performance and (b) simulation for the projection of future climate change. For the model evaluation, we performed the present-day climate simulation at $40-\mathrm{km}$ horizontal resolution for 30 -year periods (1979-2008) considered as a present-day/current/reference climate. In the present study, we simulated an Atmospheric Model Intercomparison Project (AMIP) type present-day climate using a GME $(40 \mathrm{~km})$ with sea surface temperature (SST) and sea ice concentration (SIC) data observed by the National Centre for Atmospheric Research (NCAR) following a procedure described by Hurrell et al. (2008). For the future climate projection, GME was first integrated for the presentday climate from 1979 to 2009 and sequentially for future climate simulation from 2010 to 2100 with the future SST and SIC boundary conditions. These boundary data are the projected SST and SIC of the Centro Euro-Mediterraneo sui Cambiamenti Climatici Climate Model (CMCC-CM) of the Coupled Model Intercomparison Project phase 5 (CMIP5) participating models based on the Representative Concentration Pathway (RCP) scenarios by IPCC Fifth Assessment Report (AR5). The CMCC-CM model has a relatively high resolution $\left(0.75^{\circ} \times 0.75^{\circ}\right)$ in the CMIP5 models group. The specification of this model is well summarized in Table 2. Both observed and projected SST and SIC data are converted into daily data using linear interpolation technique. We used the changes in

Table 1 Detailed descriptions of the GME model configuration

\begin{tabular}{ll}
\hline Model configuration & \\
\hline Horizontal resolution & $40 \mathrm{~km}$ (ni192) \\
Grid points & $900 \times 451$ \\
Vertical levels & 40 (top at $10 \mathrm{hPa})$ \\
Time step & $133.33 \mathrm{~s}$ \\
Convection scheme & Tiedtke (1989) \\
Cloud microphysics & Doms and Schättler (2003) \\
Radiative transfer of solar and thermal & Ritter and Geleyn (1992) \\
$\quad$ radiation & \\
Vertical turbulent fluxes & Müller (1981) \\
Subgrid-scale orographic effects & Lott and Miller (1997) \\
Soil model & Heise and Schrodin (2002) \\
\hline
\end{tabular}

$\mathrm{CO}_{2}$ concentration and other greenhouse gasses yearly from the RCP database (reference: http://www.iiasa.ac.at/web-apps $/ \mathrm{tnt} / \mathrm{RcpDb}$ ) for future climate simulation.

The model performance was tested in the present-day climate simulation for summer precipitation (June to August; JJA) using the Global Precipitation Climatology Project (GPCP; Adler et al. 2003; Huffman et al. 2009) and the CPC Merged Analysis of Precipitation (CMAP; Xie and Arkin 1997) datasets available on $2.5^{\circ}$ latitude/longitude grids for 30 years (1979-2008).

\section{Interannual variabilities and statistical relationships of South and East Asian summer monsoon precipitation}

Before examining the projected future teleconnections between the two broad Asian monsoon regions, we have tested the performance of GME by evaluating the seasonal summer precipitation (JJA) variabilities and correlation coefficient (CC) for the current climate condition. Figure 1 illustrates the interannual variabilities in seasonal summer precipitation over the South (Indian sub-continent) and East Asia regions from 1979 to 2008. Figure 1a, b shows the details of the interannual variabilities for the observed (GPCP and CMAP) and Fig. 1c for GME-simulated precipitation over South Asia (black solid lines) and East Asia (red solid lines). A comparison of interannual precipitation variabilities clearly presents an inverse relationship between South and East Asia blocks in the GPCP and CMAP (observed) as well as in the GME model. To examine the strength of the relationship between the two Asian blocks, we have computed the CCs between the standardized summer precipitation anomalies of South and East Asia. The analysis found CCs of -0.22 and -0.23 for the GPCP and CMAP, and -0.68 for GME.

To get more insight into EASM teleconnections with ISM, the East Asian block is divided into three sub-regions, namely North China, Korea-Japan and Southern China. Then the $\mathrm{CCs}$ are computed between the precipitation of each EASM region with that over the entire ISM and EASM during JJA for GPCP, CMAP and GME during the present-day climate condition as shown in Fig. 2. The precipitation variations over the South Asian block (ISM: North India) shows an in-phase relationship with North China and out-of-phase relationship with Korea-Japan (Fig. 2a, e, j). The CC pattern of precipitation over North China shows an in-phase relationship (red patches) with North India in GPCP, CMAP and GME (Fig. 2b, $\mathrm{f}, \mathrm{j}$ ), while precipitation time series over Korea-Japan shows

Table 2 Specifications of the CMCC-CM model

\begin{tabular}{lllll}
\hline Model name & Resolution, Lon. $\times$ Lat. & Institution & Country & Reference \\
\hline CMCC-CM & $0.75^{\circ} \times 0.75^{\circ}$ & Centre Euro-Mediterraneo sui Cambiamenti Climatici & Italy & Scoccimarro et al. (2011) \\
\hline
\end{tabular}




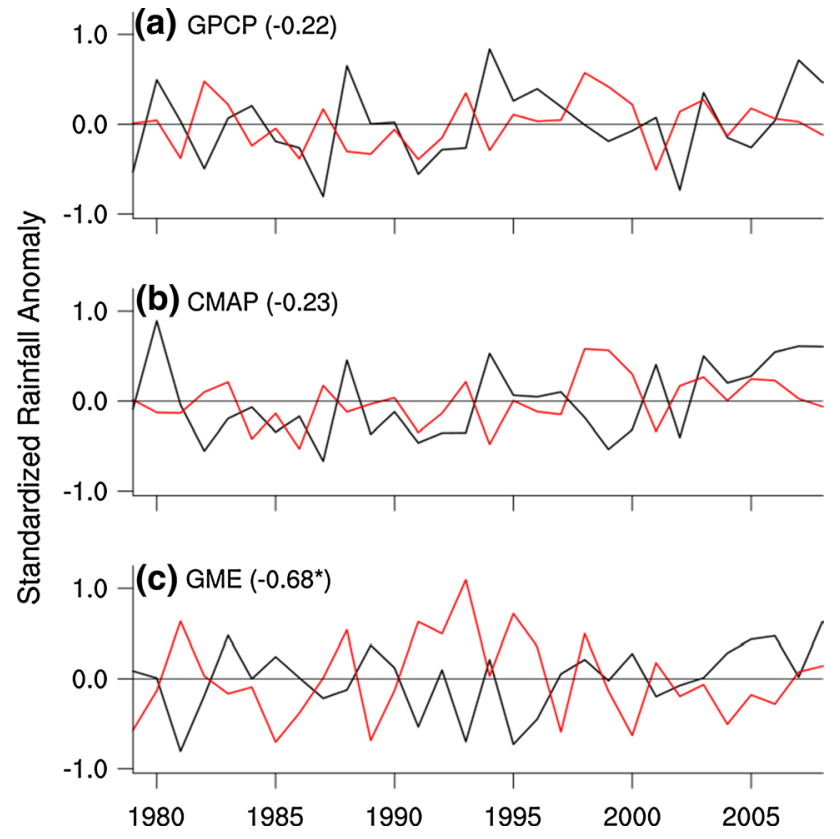

Fig. 1 Interannual variations of summer precipitation over South $\left(66^{\circ}-92^{\circ} \mathrm{E}, 20^{\circ}-35^{\circ} \mathrm{N}\right)$ and East $\left(110^{\circ}-140^{\circ} \mathrm{E}, 23^{\circ}-39^{\circ} \mathrm{N}\right)$ Asia for the period 1979-2008 for a GPCP, b CMAP and $\mathbf{c}$ GME. Black and red lines represent the South and East Asia regions an out-of-phase relationship (blue and red patches) with South Asia (Fig. 2c, g, k). Precipitation variation over Southern China shows an out-of-phase relationship with North India in GPCP and CMAP (Fig. 2d, h) and well-established inverse (an out-of-phase) relationship can be seen in GME (Fig. 2l) also. The above analysis supports the finding of Preethi et al. (2017a) and Wu (2017) between the two Asian blocks. Overall, the high-resolution model (GME) is able to capture the observed characteristics of teleconnection between the two Asian monsoon systems as mentioned in Preethi et al. (2017a, b). The model results are similar to those shown in these two papers and recommend the use of GME for the regional climate change study under global warming.

\section{Future projected trend in Asian summer monsoon components}

The GME-projected seasonal summer precipitation variations over South and East Asia on the interannual and multi-decadal timescales have been presented in Fig. 3 for the period 2010-2100 with the RCP4.5 and RCP8.5 scenarios. Figure 3 also depicts the 11 years low pass-filtered anomalies superimposed on the interannual timescales to examine the better climate trend in summer precipitation. On an interannual timescale, Fig. 3a, b illustrates the occurrences of high (low) rain years over East Asia (a) GPCP

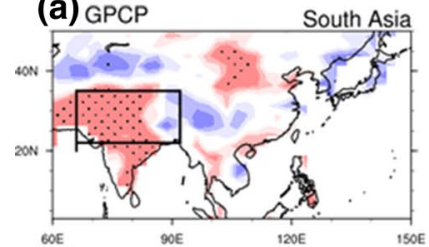

(e) CMAP

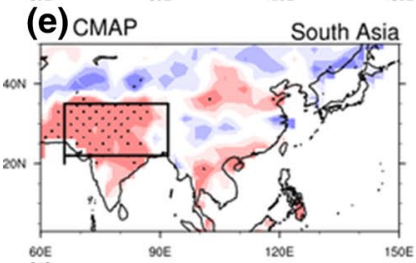

(i) GME

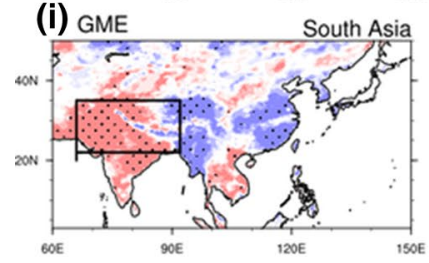

(b) GPCP

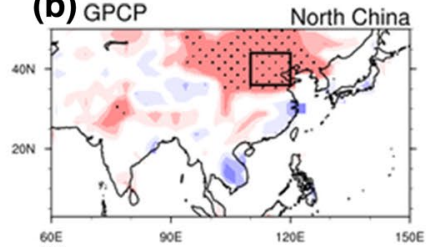

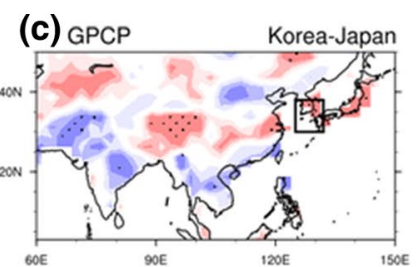
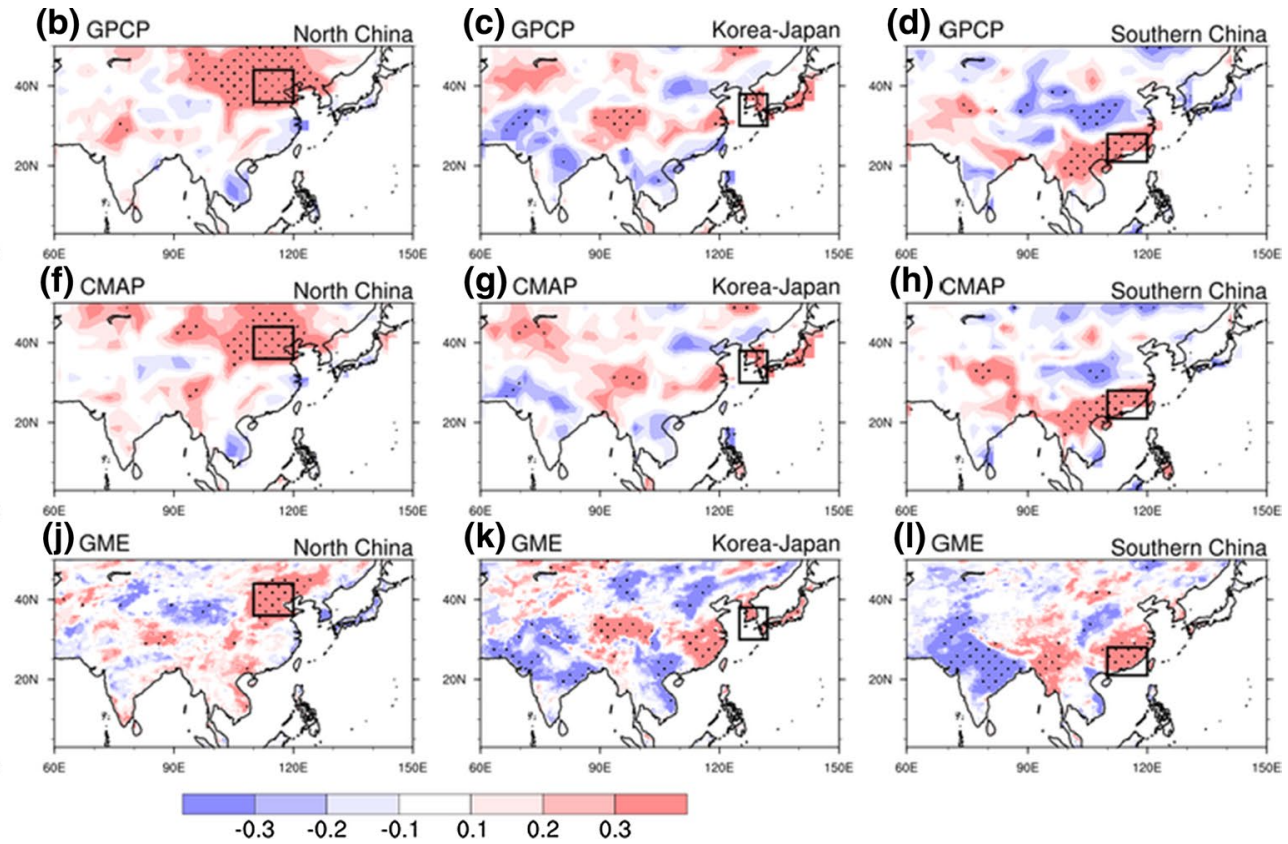

Fig. 2 Correlation coefficient (CC) pattern between summer precipitation over South Asia $\left(66^{\circ}-92^{\circ} \mathrm{E}, 20^{\circ}-35^{\circ} \mathrm{N}\right)$, North China $\left(110^{\circ}-\right.$ $\left.120^{\circ} \mathrm{E} ; 36^{\circ}-44^{\circ} \mathrm{N}\right)$, Korea-Japan $\left(125^{\circ}-132^{\circ} \mathrm{E} ; 30^{\circ}-38^{\circ} \mathrm{N}\right)$ and South China $\left(110^{\circ}-120^{\circ} \mathrm{E} ; 21^{\circ}-28^{\circ} \mathrm{N}\right)$ with that over the entire South and
East Asia regions during the present-day climate condition (19792008) for the GPCP (a-d), CMAP (e-h) and GME models (i-l). Black box indicates the regions used in the CCs computation and dots indicate a level of significance at the $95 \%$ level 
Fig. 3 Model-projected interannual (dotted line) and multi-decadal (solid line) summer precipitations over South $\left(66^{\circ}-92^{\circ} \mathrm{E}, 20^{\circ}-35^{\circ} \mathrm{N}\right)$ and East $\left(110^{\circ}-140^{\circ} \mathrm{E}, 23^{\circ}-39^{\circ} \mathrm{N}\right)$ Asia during 2010-2100 under the two RCP scenarios. Multidecadal variations are obtained by the 11-year moving average normalized by their respective standard deviations. Black and red contours represent the South and East Asia regions

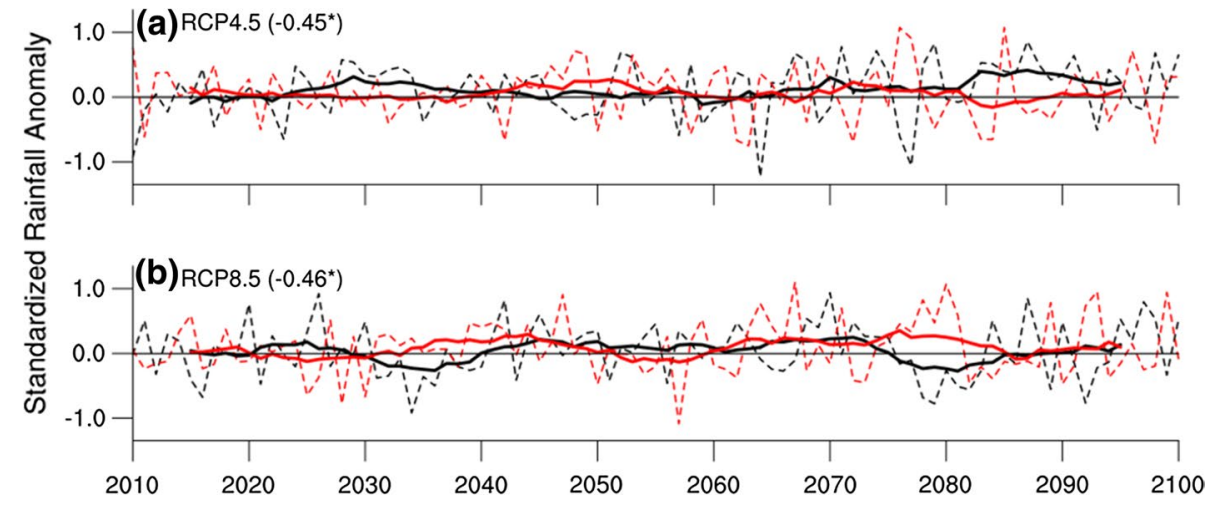

(South Asia) and vice versa. A comparison of Fig. 3a, b indicates that the RCP8.5 presents a stronger and longer decadal trend as compared to RCP4.5. The RCP8.5 (Fig. 3b) clearly shows a positive trend over South Asia after 2020-2030, a negative trend from 2030 to 2040, followed by a positive trend from 2040 to 2070 and finally a negative trend before the 2090s. While over East Asia, Fig. 3b shows a negative trend after 2020-2030, the positive trend exists from 2030 to 2050 followed by a decreasing trend from 2050 to 2060 and finally an increasing trend after 2060 (completely reverse trend with South Asia). It is interesting to note that there is a longer period (decadal) of positive trend over East Asia compared to South Asia. It reveals that East Asia has a higher possibility of getting high precipitation compared to South Asia during the twenty-first century.

Statistical correlation of the projected seasonal summer precipitation between the two Asian blocks shows a significant and inverse CCs of -0.45 and -0.46 (both significant at $0.1 \%$ level) with the RCP4.5 and RCP8.5, respectively, for the period 2010-2100. To get detailed information about the temporal relationship between the two Asian monsoon components, the CCs are computed for different time slices (near, mid and far futures) in the future. The analysis found a significant and inverse CC of -0.48 (significant at the $1 \%$ level) in near (2010-2039) for both the RCP scenarios. The CCs were -0.34 and -0.36 (both significant at the $5 \%$ level) in mid (2040-2069) and CCs of -0.56 and -0.60 (both significant at the $0.1 \%$ level) for far future (2070-2099) with RCP4.5 and RCP8.5, respectively. It is interesting to note that a significant inverse relationship was found between the South and East Asian monsoon regions not only during the entire period of study, but also during different time slices under both the RCP scenarios. The present analysis found a consistent significant inverse relationship between the two Asian blocks in future and the strongest inverse relationship during the far future time slice.

\subsection{Future projected trend in regional EASM precipitation}

The present study examined the changes in future projected regional precipitation over East Asia along with the South Asia block. The interannual and multi-decadal (11 years moving average) variabilities over the three regions of East Asia and South Asia are depicted in Fig. 4 for the RCP4.5 and RCP8.5 scenarios. A comparison of the epochal changes in future projected summer precipitation over North China, Korea-Japan and Southern China with South Asia (Fig. 4) clearly shows that North China follows an almost similar trend to that of South Asia, while Korea-Japan and Southern China depict an opposite trend with respect to South Asia. It is interesting to note that all the three regions of East Asia have presented a larger amplitude of interannual and multi-decadal precipitation variabilities than South Asia. Figure 4b, c, e, f reveals that Korea-Japan and Southern China follow almost similar epochs of high and low rain decades of the East Asian block (Fig. 3), such as an increasing trend during 2030-2050 and 2060-2080 and decreasing trend in 2020-2030 and 2050-2060. However, the trend over North China (Fig. 4a, d) follows that of South Asia instead of East Asia as a whole (as shown in Fig. 3).

Overall, the present analysis suggests that North China follows the precipitation variation and trend of South Asia, while Korea-Japan and Southern China exhibit an almost similar trend to that of East Asia and a completely reverse trend from that of the South Asian block.

\section{Projected future relationship between South and East Asian monsoon precipitation}

A spatial correlation analysis has been performed to project the possible teleconnections between South and East Asian monsoon precipitation during near (2010-2039), mid 

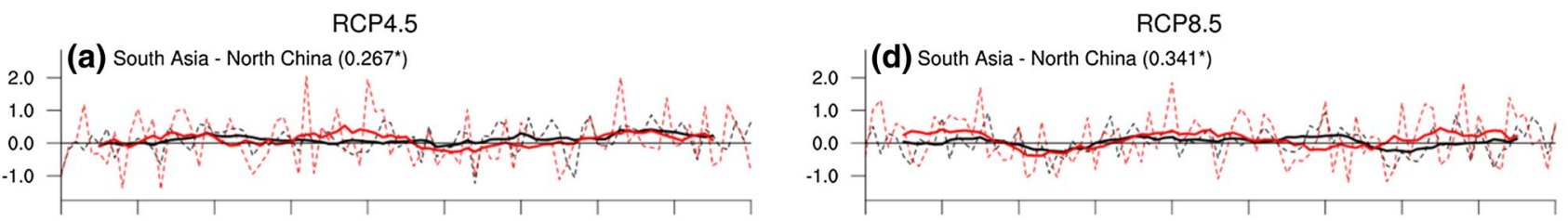

(b) South Asia - Korea-Japan (-0.335*)
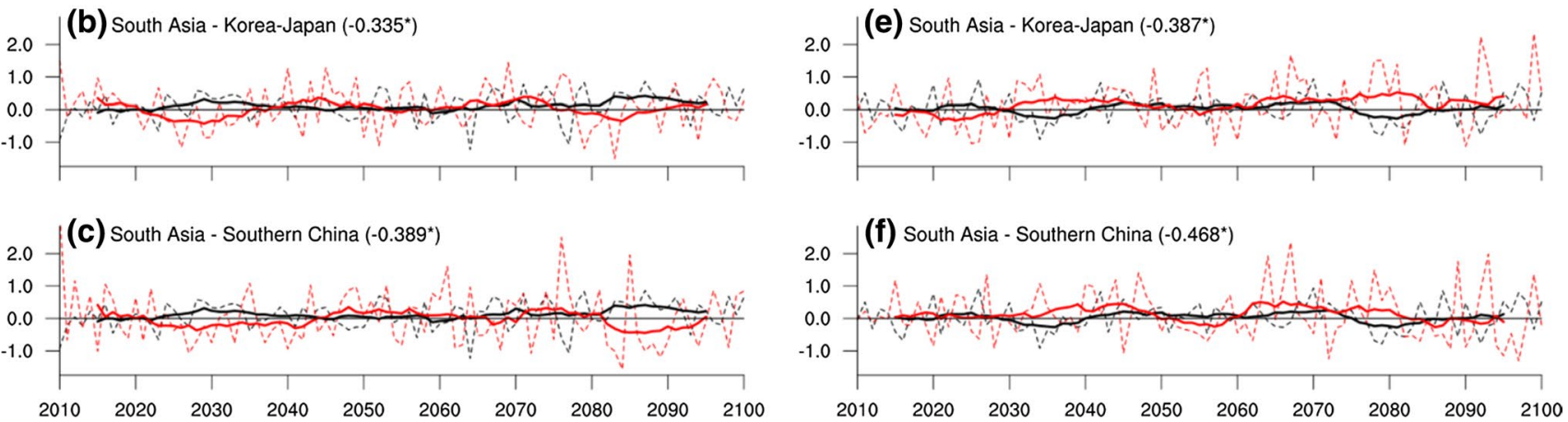

Fig. 4 Model-projected interannual (dotted line) and multi-decadal (solid line) summer precipitations over South Asia $\left(66^{\circ}-92^{\circ} \mathrm{E}, 20^{\circ}-\right.$ $35^{\circ} \mathrm{N}$ ) and three different regions of East Asia (North China; $110^{\circ}$ $120^{\circ} \mathrm{E} ; 36^{\circ}-44^{\circ} \mathrm{N}$, Korea-Japan; $125^{\circ}-132^{\circ} \mathrm{E} ; 30^{\circ}-38^{\circ} \mathrm{N}$, Southern China; $110^{\circ}-120^{\circ} \mathrm{E} ; 21^{\circ}-28^{\circ} \mathrm{N}$ ) during $2010-2100$ under the RCP4.5

(2040-2069) and far (2070-2099) futures with both the RCP scenarios. To get more insight into the projected EASM teleconnections with the South Asian block, the model-simulated summer precipitation time series over three regions of East Asia as mentioned in Sect. 3 and a large region of North India (south block shown by a black rectangle; where larger changes in precipitation are noticed) were examined. To understand the possible causes of any such relationships, we have also investigated the teleconnections of the mean sea level pressure (MSLP) and wind field at $850 \mathrm{hPa}$ over the Indo-Pacific regions with the precipitation over South Asia, North China, Korea-Japan and Southern China separately for the same three time slices in future.

\subsection{Details of the relationship between South and East Asian summer precipitation}

In the present study, $\mathrm{CC}$ patterns are shown between the model-projected summer (JJA) precipitation of each region of East Asia and a region of South Asia with that over the entire South and East Asian precipitation. Those CC patterns are displayed in Figs. 5 and 6 during near, mid and far future climates for the RCP4.5 and RCP8.5 scenarios, respectively. The dotted points show the level of significance at $95 \%$.

The CC displaying the pattern of South Asian monsoon precipitation clearly shows an in-phase relationship with the precipitation variations over North China and an out-ofphase relationship with Korea-Japan and Southern China

and RCP8.5 scenarios. Multi-decadal variations are obtained by the 11-year moving average normalized by their respective standard deviations. Black and red contours represent the South Asia and three regions of the East Asian regions

consistently from near to far future time slices with both the scenarios (Figs. 5a, e, i, 6a, e, i). The strongest CC pattern is noticed during far future under both the scenarios (denoted by larger covered areas by red and blue patches with dots). The CC pattern of the Korea-Japan region depicts an outof-phase relationship with large parts of North India and in-phase relationship with Southern China from near to far future periods under both the scenarios. A comparison of relationships during different time slices indicates the strongest relationship in the far future, followed by near future and the weakest during mid-future with RCP4.5 (Fig. 5c, g, k) and RCP8.5 (Fig. 6c, g, k). Finally, the CC pattern of precipitation variations over Southern China shows an out-of-phase relationship with the South Asia block. The strength of relationship between Southern China and South Asia has not changed significantly from near to far future with RCP4.5 (Fig. 6d, h, l). A major change in CC is noticed with RCP8.5 (Fig. 6d, h, 1), where it presents the strongest and inverse (out-of-phase) associations with South Asia during the near and far future and the weakest in the mid-future.

Overall, the present study found an in-phase relationship between the precipitation variation over North China and South Asia. Whereas precipitation time series over Korea-Japan and Southern China show an out-of-phase relationship with that of South Asia, the projected CC pattern follows a similar trend of current climate except with the changing CCs strength during different time slices. It is also noted that the projected teleconnections of the South Asia block with the various regions of East Asia show large 
RCP4.5

(a) Near-Future

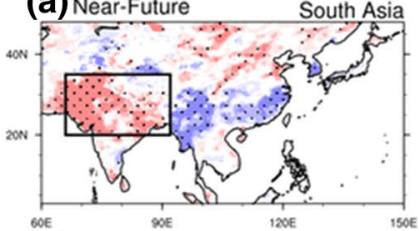

(e) Mid-Future
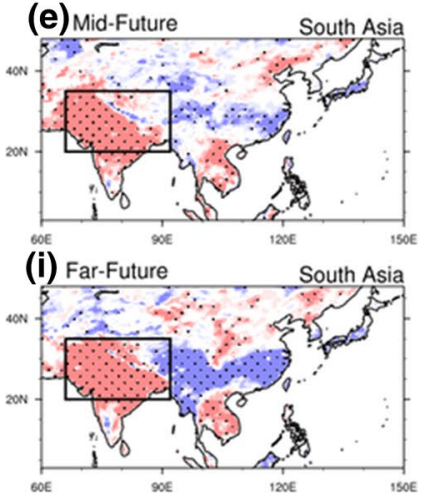

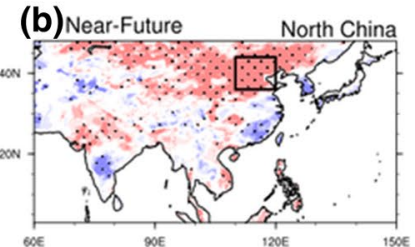

(f) Mid-Future
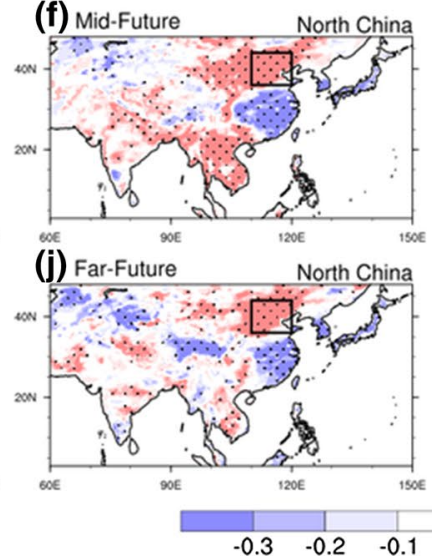

(c) Near-Future

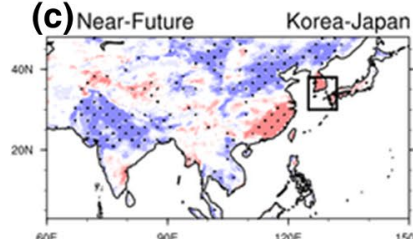

(g) Mid-Future $\quad$ Korea-Japan

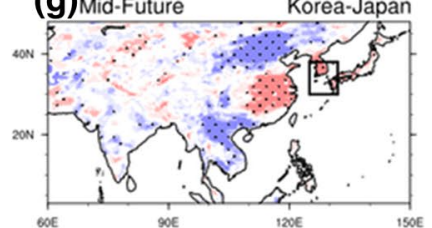

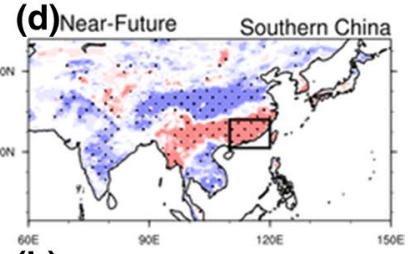
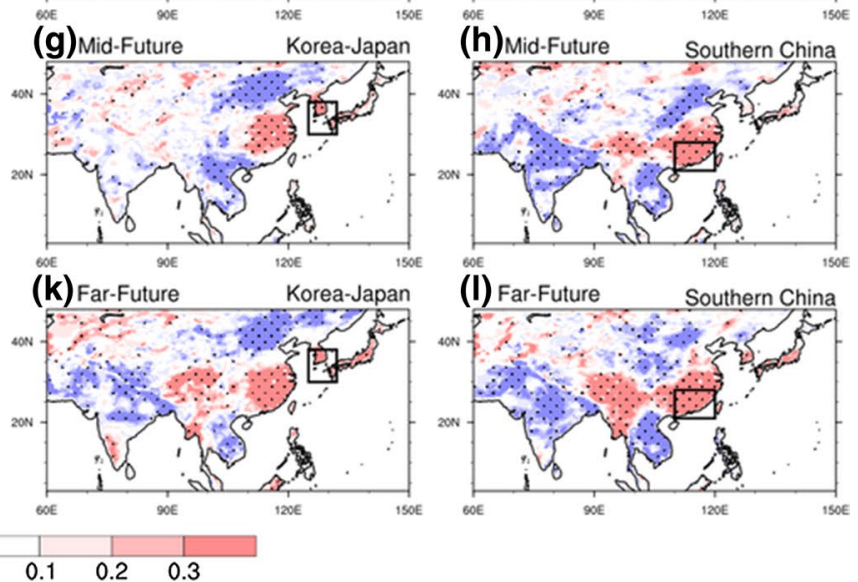

Fig. 5 CC patterns between model-projected seasonal summer precipitation and with that simulated over South Asia $\left(66^{\circ}-92^{\circ} \mathrm{E}, 20^{\circ}-\right.$ $\left.35^{\circ} \mathrm{N}\right)$, North China $\left(110^{\circ}-120^{\circ} \mathrm{E} ; 36^{\circ}-44^{\circ} \mathrm{N}\right)$, Korea-Japan $\left(125^{\circ}-\right.$ $\left.132^{\circ} \mathrm{E} ; 30^{\circ}-38^{\circ} \mathrm{N}\right)$ and South China $\left(110^{\circ}-120^{\circ} \mathrm{E} ; 21^{\circ}-28^{\circ} \mathrm{N}\right)$ in near
(2010-2039), mid (2040-2069) and far futures (2070-2099) under RCP4.5. Black box indicates the specific regions used in CCs computation and dots indicate a level of significance at the $95 \%$ level

\section{RCP8.5}

(a) (a) reveno

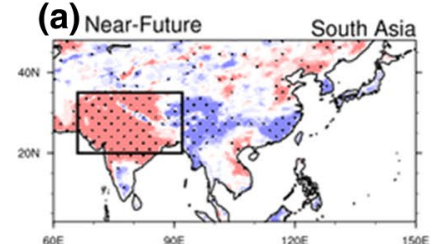

(e) Mid-Future
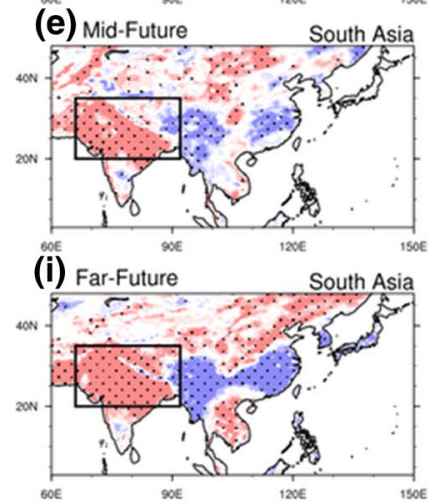

(b) Near-Future
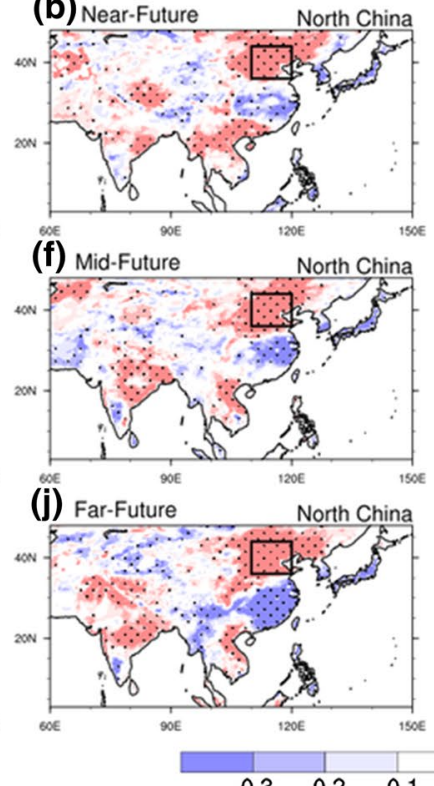

(c) Near-Future
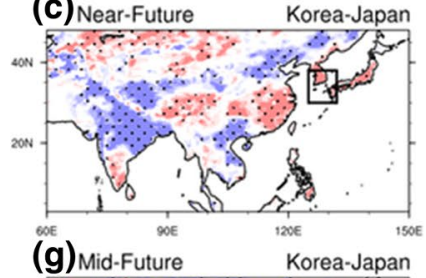

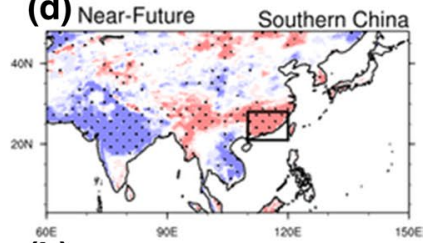

(d) Near-Future Southern China
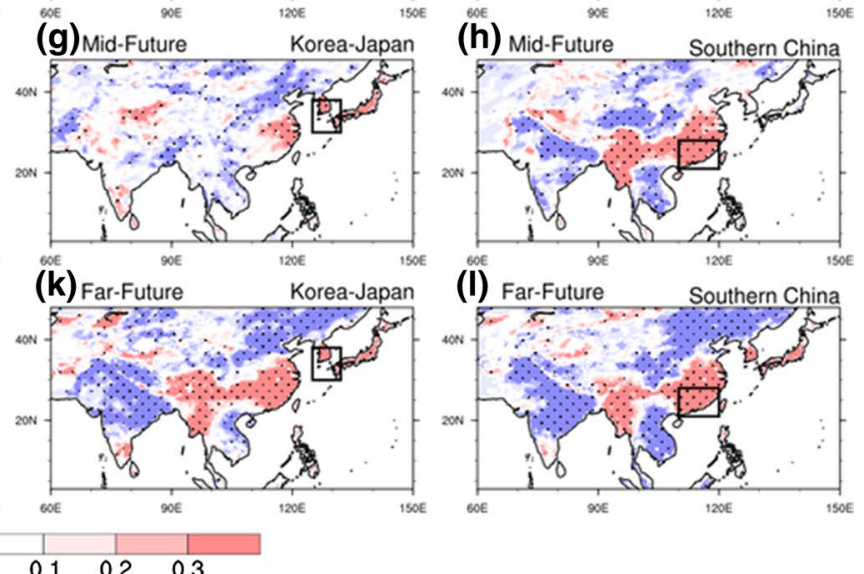

Fig. 6 Same as in Fig. 5 except for the RCP8.5 scenario 
changes in the strength of temporal CCs, with the strongest in the far future and weakest in the mid-future.

\subsection{Mean sea level pressure}

The statistical association of the MSLP field with the summer precipitation over South Asia and three sub-regions of East Asia (North China, Korea-Japan and Southern China) during three time slices in future (near, mid and far futures) are presented here. The spatial correlation patterns are displayed in Fig. 7 for RCP4.5 and Fig. 8 for RCP8.5 scenarios.

For near future, the CC pattern of MSLP field with the precipitation over South Asia illustrates negative CCs over large parts of North India and positive CCs over the Pacific (Fig. 7a, e, i), especially during the mid and far futures with RCP4.5. A similar CCs pattern can be seen with RCP8.5, except a wider areal spread of positive CCs from near to far future and a slight westward spread in the near future

RCP 4.5
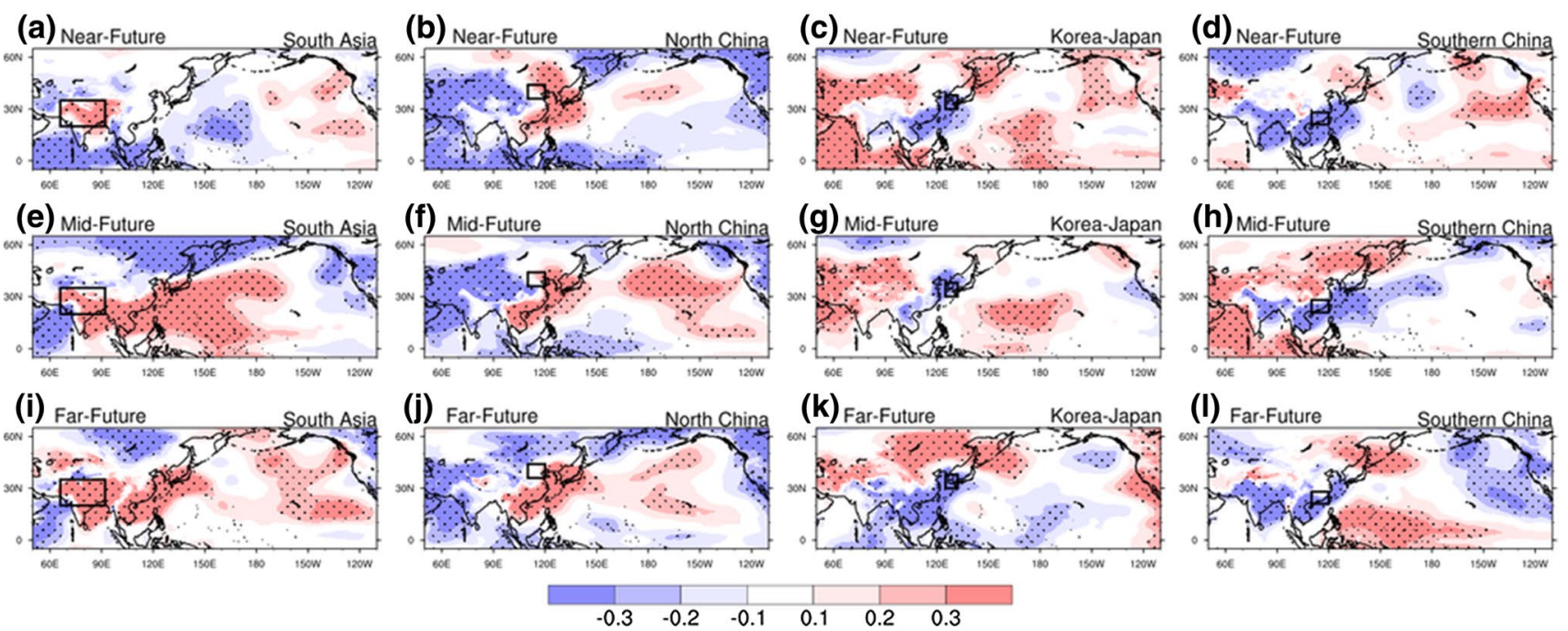

Fig. 7 CCs pattern between model-projected MSLP field and seasonal summer precipitation over South Asia $\left(66^{\circ}-92^{\circ} \mathrm{E}, 20^{\circ}-35^{\circ} \mathrm{N}\right)$, North China $\left(110^{\circ}-120^{\circ} \mathrm{E} ; 36^{\circ}-44^{\circ} \mathrm{N}\right)$, Korea-Japan $\left(125^{\circ}-132^{\circ} \mathrm{E}\right.$; $\left.30^{\circ}-38^{\circ} \mathrm{N}\right)$ and South China $\left(110^{\circ}-120^{\circ} \mathrm{E} ; 21^{\circ}-28^{\circ} \mathrm{N}\right)$ in near $(2010$

2039), mid (2040-2069) and far future (2070-2099) under RCP4.5. Black box indicates the specific regions used in CCs computation and dots indicate a level of significance at the $95 \%$ level

\section{RCP8.5}
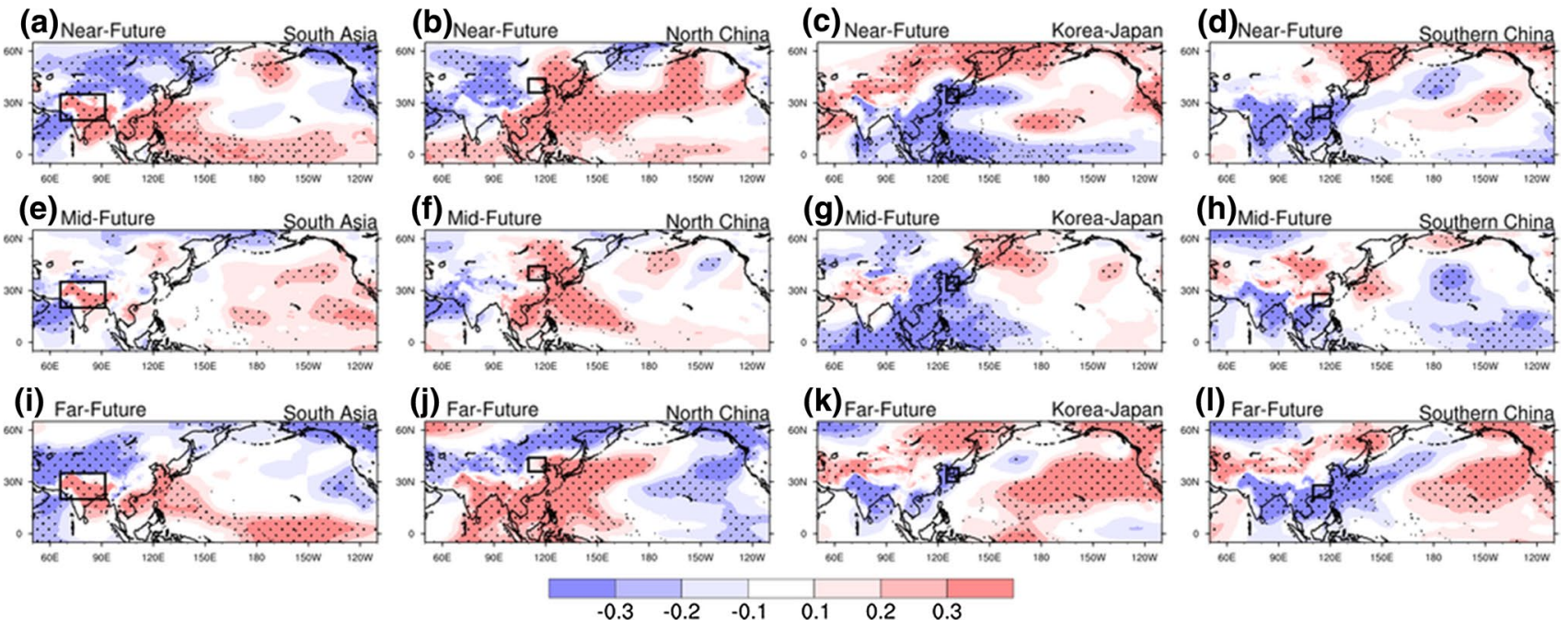

Fig. 8 Same as in Fig. 7 except for the RCP8.5 scenario 
(Fig. 7a, e, i). The pattern displaying CC suggests a low pressure over India and a high pressure over west Pacific will be conducive for high precipitation over the Indian sub-continent (it suggests that the water vapor gets transported from the West Pacific over the South Asia block). The CC pattern of MSLP field with the precipitation over North China (Fig. 7b, f, j) depicts significant positive CC over Pacific (especially, West Pacific) and negative CCs from the Arabian Sea to North India from near to far future with RCP4.5. A similar CC pattern can be seen with RCP8.5 (Fig. 8b, f, j), except a wider westward spread of significant positive $\mathrm{CC}$ over the Pacific and north Indian Ocean, especially in the near and far futures (Fig. 8b, f, j). A comparison of the CC pattern over South Asia and North China shows a nearly similar pattern, i.e., negative CCs spread over North India and positive CCs over the West Pacific (with RCP8.5).

The CC pattern between the MSLP field and precipitation variation over Korea-Japan presents positive CCs over North India and the East Pacific and negative CC over the West Pacific (Fig. 7c, g, k), indicating high pressure over India (generally leads to weak monsoon condition over India), and low pressure over Changma front leads to high precipitation over Korea-Japan. The CC pattern with the RCP8.5 (Fig. 8c, g, k) follows a similar pattern as noticed with RCP4.5 (Fig. 7a, g, k) except a wider spread of significant positive and negative CCs. Comparing the spatial pattern of significant negative and positive CCs of MSLP field with the precipitation over Korea-Japan region and with South Asia, analysis noticed a completely reverse pattern of positive and negative CCs (out-of-phase relationship) between the two Asian monsoon regions. The relationship between precipitation over Southern China and MSLP (Fig. 7d, h, l) field with RCP4.5 shows negative CCs over the South China Sea (SCS) and Bay of Bengal (BoB) and positive CCs over North India and North China indicating high-pressure field over India, and low pressure over SCS and $\mathrm{BoB}$ is associated with good monsoon activity over Southern China. The CC pattern with RCP8.5 (Fig. 8d, h, 1) also shows a similar pattern as noticed in RCP4.5, except for a slightly wider extent of the significant CCs especially during near and far future climate.

Overall, the spatial correlation analysis reveals that the precipitation variations over the South Asia block and North China exhibit approximately a similar pattern of CC with the MSLP field, while Korea-Japan and Southern China present completely inverse CC pattern to that of the South Asia block.

\subsection{Wind at $850 \mathrm{hPa}$}

As is known, the South and East Asian summer monsoon precipitations are teleconnected through atmospheric circulation which controls the transport of the atmospheric water vapor from the tropical South Asia to East Asia and contributes largely to precipitation variabilities over the regions. Some of the studies have found that the water vapor enters over East Asia by the anomalous lower level wind associated with the South Asian monsoon component (Zhang 2001; Liu and Ding 2008). Therefore, the present study has attempted to examine the teleconnection between tropospheric winds at the lower level $(850 \mathrm{hPa})$ and precipitation variations over the two Asian monsoon systems. The CC pattern between the wind at $850 \mathrm{hPa}$ and precipitation variabilities over South Asia, North China, Korea-Japan and Southern China have been studied for the same three time slices in future and with the same two scenarios as mentioned in the earlier sections. Here, Figs. 9 and 10 present the spatial CC patterns in near, mid and far future for the RCP4.5 and RCP8.5 scenarios, respectively.

The CC pattern between atmospheric circulation field at $850 \mathrm{hPa}$ and precipitation over South Asia is significantly correlated to the strength of the southwesterlies over the Arabian Sea, thereafter striking on eastern Himalaya. A large part is deflected toward northwest India, indicating an elongated zone of monsoon trough over the Indo-Gangetic plains (Figs. 9a, e, i, 10a, e, i). A part of the southwesterly moves toward East Asia and after merging with the southeasterly from the west Pacific moves toward North China as the southwesterly flow. The CC displaying the pattern between the precipitation over South Asia and the lower tropospheric wind $(850 \mathrm{hPa})$ shows stronger southwesterlies during the near and far future, whereas weaker southerlies over the main South Asian region (weaker cyclonic circulation over the summer heat low region) can be seen in midfuture under the RCP4.5 scenario (Fig. 9a, e, i). A similar CC pattern is noticed with RCP8.5 (Fig. 10a, e, i) except a strong anticyclonic circulation over Korea-Japan in the mid-future. Another interesting feature of CC pattern is an occurrence of low-pressure area (cyclonic circulation) over the $\mathrm{BoB}$ in the near and far futures and slightly weaker in the mid-future under both the scenarios.

The CC pattern between the precipitations over North China and the wind at $850 \mathrm{hPa}$ (Figs. 9b, f, j, 10b, f, j) shows that water vapor gets transported toward North China through the southwesterlies. There is an indication for the southwesterlies over BoB and these southwesterlies generally merge with the southeasterlies from the West Pacific. After merging, it moves like the southwesterly over North China and causes precipitation over that region (Fig. 10b, $f, j)$. The CC pattern of precipitation variability over the Korea-Japan sector and the lower level wind illustrate that larger parts of moisture enter the Korea-Japan sector by the southwesterly flow along the western limb of the NPSH (Figs. 9c, g, k, 10c, g, k). It is worth noting that a cyclonic circulation shifted eastward leads to stronger southwesterly flow toward the Korea-Japan region, contributing largely 
RCP4.5

(a) Near-Future

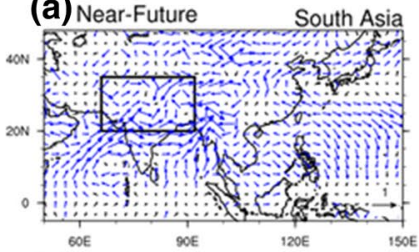

(e) Mid-Future
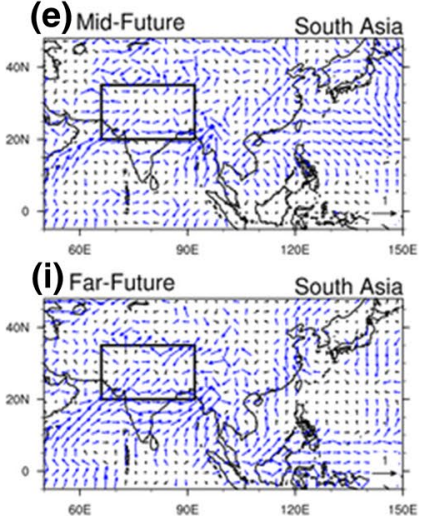

(b) Near-Future

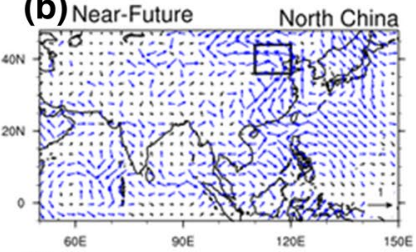

(c) Near-Future

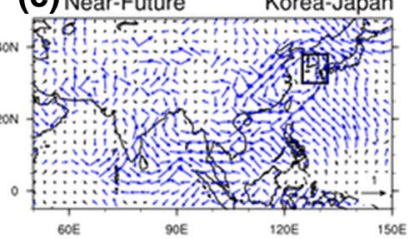

(g) $)_{\text {Mid-Future }}^{60 E}$
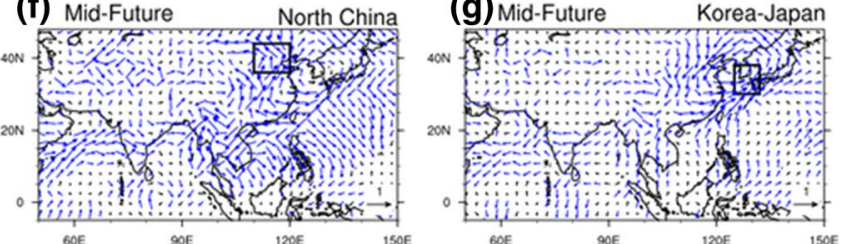

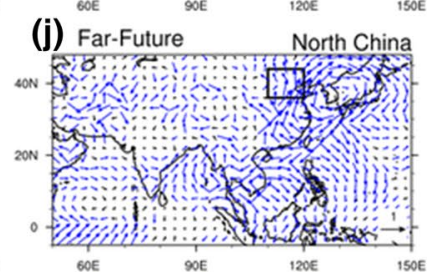

Fig. $9 \mathrm{CCs}$ pattern between model-projected wind field at $850 \mathrm{hPa}$ and seasonal summer precipitation over South Asia $\left(66^{\circ}-92^{\circ} \mathrm{E}, 20^{\circ}-\right.$ $\left.35^{\circ} \mathrm{N}\right)$, North China $\left(110^{\circ}-120^{\circ} \mathrm{E} ; 36^{\circ}-44^{\circ} \mathrm{N}\right)$, Korea-Japan $\left(125^{\circ}-\right.$ $\left.132^{\circ} \mathrm{E} ; 30^{\circ}-38^{\circ} \mathrm{N}\right)$ and South China $\left(110^{\circ}-120^{\circ} \mathrm{E} ; 21^{\circ}-28^{\circ} \mathrm{N}\right)$ in
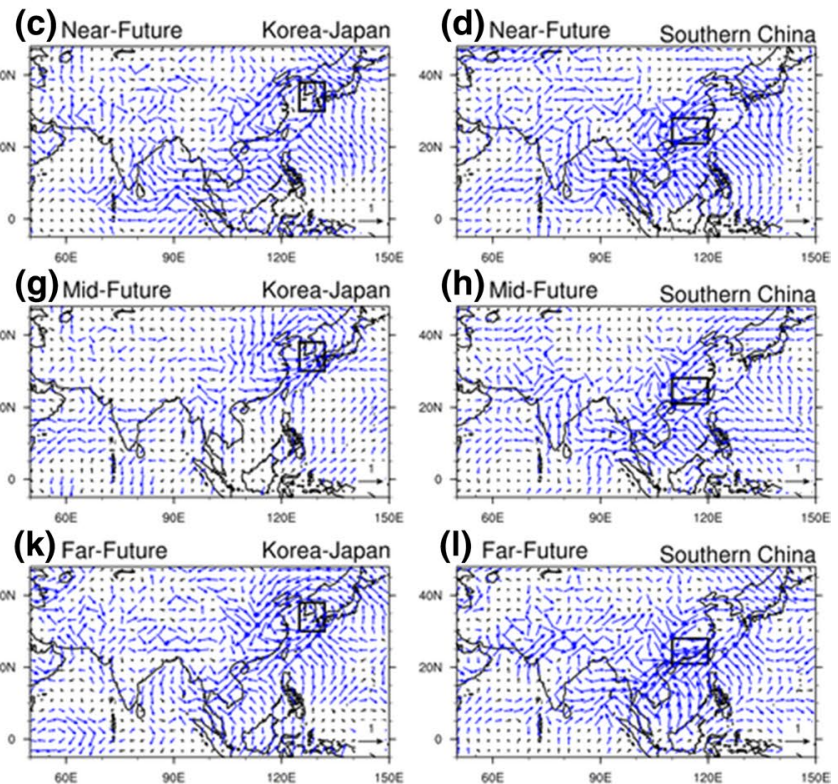

the near (2010-2039), mid (2040-2069) and far future (2070-2099) under RCP4.5. Black box indicates the specific regions used in CCs computation and blue color indicates a level of significance at the $95 \%$ level

RCP8.5
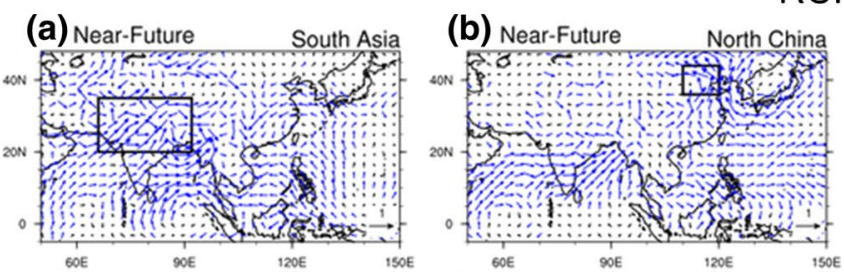

(e) Mid-Future South Asia
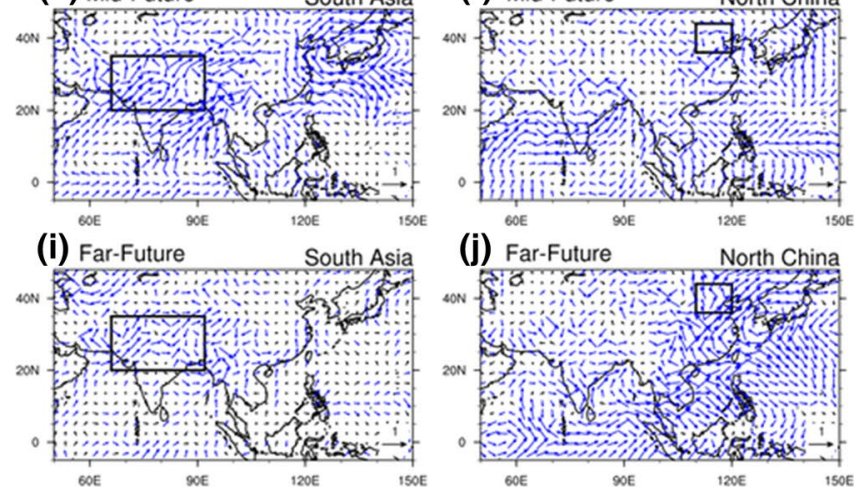
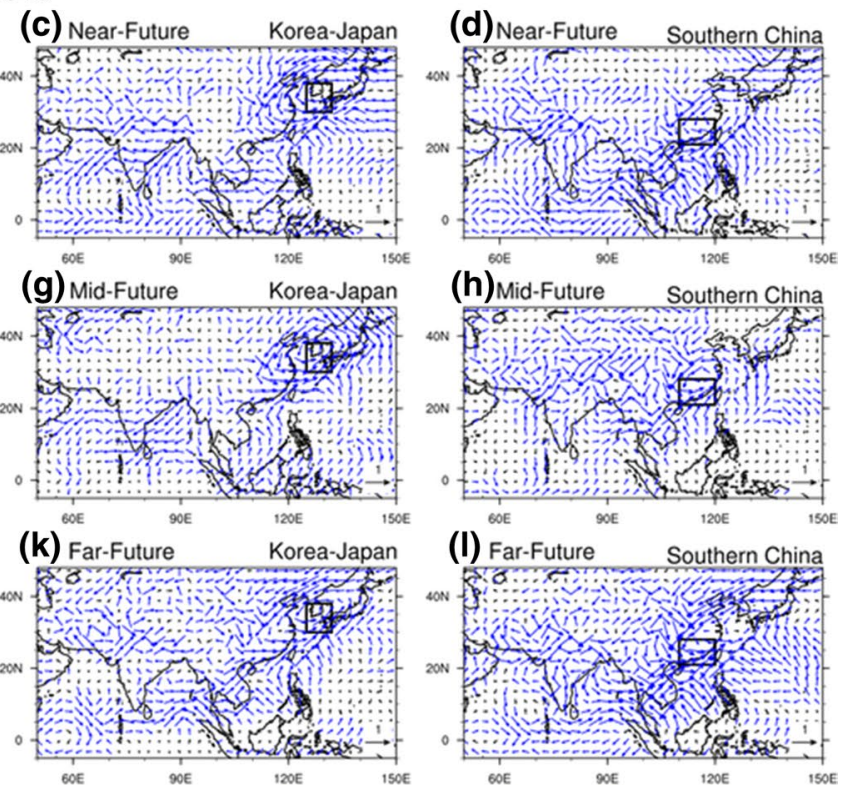

Fig. 10 Same as in Fig. 9 except for the RCP8.5 scenario

to the seasonal precipitation over those regions. However, there is an indication of parts of westerlies getting deflected from the eastern limb of the Himalaya transporting a small amount of moisture over Korea-Japan. There is also an indication of anticyclonic circulation over North India, which leads to low precipitation over South Asia. Strong cyclonic circulation over Korea-Japan and anticyclonic circulation over India can be seen during the near and far futures (causing an out-of-phase relationship). The CC pattern of wind and precipitation over Southern China shows an eastward 
wind flow from BoB that transports moistures toward Southern China (Figs. 9d, h, 1, 10d, h, l). A similar transport of moisture toward Southern China was also discussed in Zhang (2001). Another transport of moisture over Southern China can be seen from the SCS also. This suggests that the Korea-Japan sector gets a larger amount of moisture from the Western Pacific, while Southern China gets transported moistures from the SCS and BoB, both of which can be seen clearly from the spatial CC pattern as shown in Figs. 9d, h, 1 and $10 \mathrm{~d}, \mathrm{~h}, 1$. The areal extent of significant CC pattern becomes stronger in the far future compared to the midfuture under both the scenarios.

Overall, the CC pattern of lower level winds suggests a stronger (weaker) northward transport of moisture over South Asia leading to high (low) summer precipitation over East Asia, favorable for high (low) precipitation over North China (in-phase relationship with South Asia). The CC pattern between precipitations over Korea-Japan with the lower atmospheric winds shows the stronger westerlies over Southern Japan and it can be assumed as a major source of moisture over that region. The CC pattern over Korea-Japan and Southern China shows slightly wider areal extent of the significant CCs in the far future.

\subsection{Projected sliding teleconnections between South Asia and regional East Asian summer monsoon precipitation}

Observational and GME-simulated precipitation studies during the present-day climate condition (discussed in Sect. 3) suggest that the two regions of East Asia (Korea-Japan and
Southern China) exhibit an out-of-phase relationship and another region (North China) shows an in-phase relationship with the South Asia block. To investigate the detailed variations in teleconnections on multi-decadal timescales, 21-year sliding CCs of summer precipitation over North China, Korea-Japan and Southern China with the summer precipitation over South Asia were studied separately with the RCP4.5 and RCP8.5 scenarios (Fig. 11a-f). The in-phase relationship between North China and South Asia can be seen through almost all the periods of the twenty-first century, and it is projected to be the strongest after 2060s under both the scenarios. A significant and strong in-phase relationship is also projected during the near future between North China and South Asia with the RCP4.5 scenario (Fig. 11a-c). However, the Korea-Japan region exhibits significant and inverse CCs (out-of-phase relationship) with the South Asia block during the near (2010-2039) and far future (after 2070) under both the RCP scenarios (Fig. 11a, d). Southern China presents significant and strong CCs (out-ofphase relationship) with South Asia during the entire period in the far future with RCP4.5 and RCP8.5 (Fig. 11c, f) and in near future with RCP8.5 (Fig. 11f).

Overall, 21-year sliding CCs pattern shows the strongest in-phase relationship between North China and South Asia from 2060 to the end of the twenty-first century in RCP8.5. While the Korea-Japan region exhibits strong outof-phase relationship with South Asia in near (2010-2039) and far future (2070-2099) under both the scenarios, Southern China depicts out-of-phase relationship during near (2010-2039) and the strongest during far future with RCP8.5.
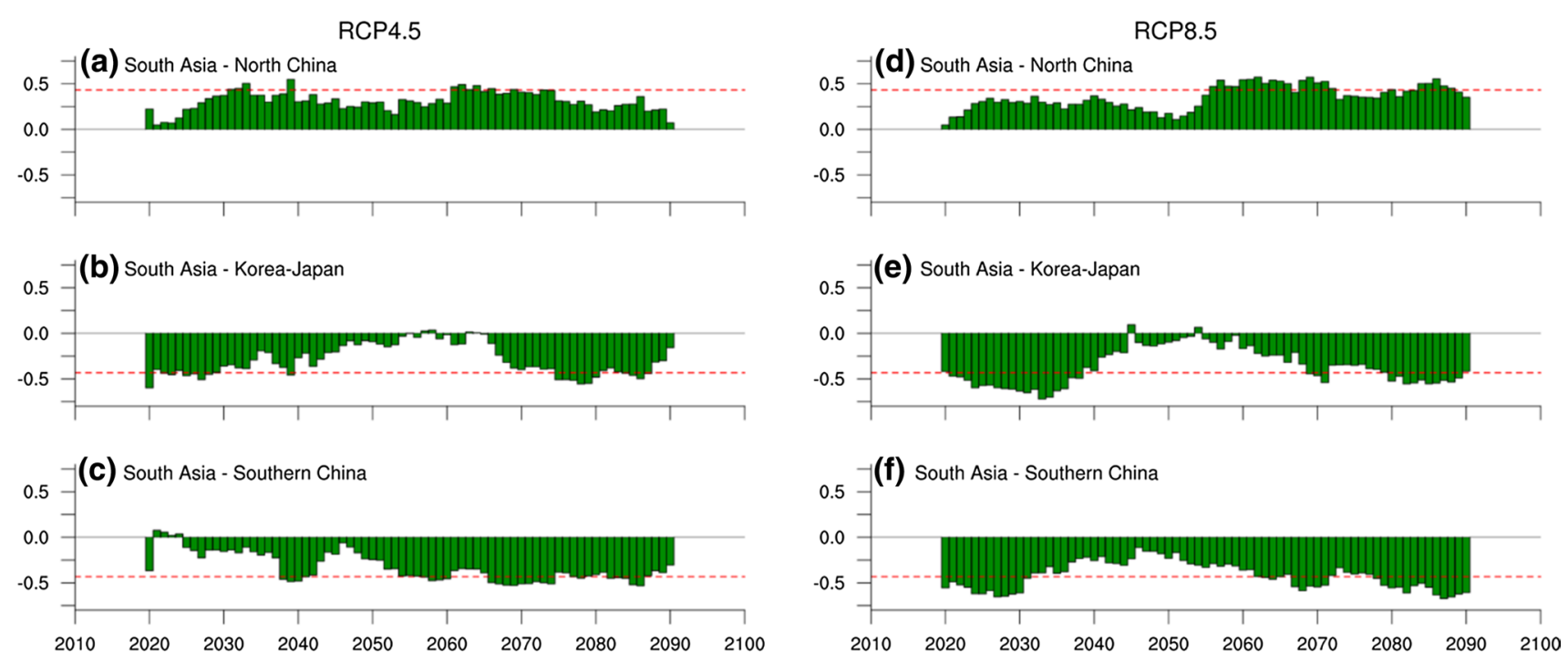

Fig. 11 Model-projected 21-year sliding CCs of summer precipitations between South Asia $\left(66^{\circ}-92^{\circ} \mathrm{E}, 20^{\circ}-35^{\circ} \mathrm{N}\right)$ and three different regions of East Asia (North China; $110^{\circ}-120^{\circ} \mathrm{E} ; 36^{\circ}-44^{\circ} \mathrm{N}$, Korea-

Japan; $125^{\circ}-132^{\circ} \mathrm{E} ; 30^{\circ}-38^{\circ} \mathrm{N}$, Southern China; $110^{\circ}-120^{\circ} \mathrm{E} ; 21^{\circ}-$ $28^{\circ} \mathrm{N}$ ) during 2010-2100 under the RCP4.5 and RCP8.5 scenarios. Red dashed lines represent a level of significance at the $95 \%$ level 


\section{Conclusions}

An investigation of the projected teleconnections between the South (Indian sub-continent) and East Asian summer monsoon seasonal precipitation was carried out using a high-resolution atmospheric general circulation GME at $40 \mathrm{~km}$ horizontal resolution during near, mid and far future time slices (each time slice consists of 30 years period) under the RCP4.5 and RCP8.5 scenarios. Following are the important results of the above study:

(a) The model projected a multi-decadal variability in precipitation over the East and South Asia blocks with some period of high rain year over East Asia and at the same time low rain over South Asia and vice versa. The analysis also noticed that on the multi-decadal timescales, the precipitation trend over North China follows the trend of the South Asian block, while Korea-Japan and Southern China follow the trend of the entire East Asia block.

(b) The CC pattern of precipitation over the South Asia block shows an out-of-phase relationship with the precipitation variations over Korea-Japan and Southern China, while there is an in-phase relationship with that over North China. The inverse (out-of-phase) relationships between the two Asian components are projected to be stronger during the near and far futures and weaker in the mid-future under both the scenarios.

(c) The 21-year sliding CC of North China shows an inphase relationship with the South Asian block, while Korea-Japan and Southern China exhibit an out-ofphase relationship with South Asia, mostly for all the periods of the twenty-first century. However, the strongest and significant inverse CCs are found during the near and far futures.

(d) With the projected CC patterns of lower tropospheric wind $(850 \mathrm{hPa})$ and MSLP fields with the precipitation over the Korea-Japan region, a major portion of moisture enters the Korea-Japan region by the southwesterly flows along the western limb of NPSH. The CC pattern of precipitation over Southern China indicates that major portions of moisture entered from the BOB and SCS in that region. The CC pattern of precipitation over South Asia with the wind and MSLP fields shows that anomalous southwesterly flows bring more moisture over India and North China from lower latitudes.

Acknowledgements This work was funded by the Korea Meteorological Administration Research and Development Program under Grant KMIPA 2015-6130, and the computing resources was supported by Partnership and Leadership for the nationwide Supercomputing Infrastructure (PLSI) Project in Korea Institute of Science and Technology Information (KISTI).
Open Access This article is distributed under the terms of the Creative Commons Attribution 4.0 International License (http://creativecomm ons.org/licenses/by/4.0/), which permits unrestricted use, distribution, and reproduction in any medium, provided you give appropriate credit to the original author(s) and the source, provide a link to the Creative Commons license, and indicate if changes were made.

\section{References}

Adler RF, Huffman GJ, Chang A, Ferraro R, Xie P, Janowiak J, Rudolf B, Schneider U, Curtis S, Bolvin D, Gruber A, Susskind J, Arkin P, Nelkin E (2003) The version 2 global precipitation climatology project (GPCP) monthly precipitation analysis (1979-present). J Hydrometeorol 4:1147-1167

Chaudhari HS (2006) Predictability and prediction of East Asian Summer Monsoon: experiments with GCM. Thesis for the Degree of Doctor of Philosophy, Department of Environmental Atmospheric Science, Pukyong National University, South Korea

Ding Y, Chan DCL (2005) The East Asian summer monsoon: an overview. Meteorol Atmos Phys 89:117-142. https://doi. org/10.1007/s00703005-0125-z

Doms G, Schättler U (2003) The nonhydrostatic limited-area model LM (Lokal-Modell) of DWD. Part I: Scientific Documentation. Deutscher Wetterdienst (DWD), Offenbach

Gadgil S (2003) Indian monsoon and its variability. Annu Rev Earth Planet Sci 31:429-467. https://doi.org/10.1146/annurev.eart h.31.100901.141251

Goswami BN (2005) The Asian monsoon: interdecadal variability. The Asian Monsoon. In: Wang B (ed) Springer, pp 295-327

Heise E, Schrodin R(2002) Aspects of snow and soil modelling in the operational short range weather prediction models of the German Weather Service. J Com Tec 7:121-140. Special Issue: Proceedings of the International Conference on Modelling, Databases and Information Systems for Atmospheric Science (MODAS), Irkutsk, Russia, June 25-29, 2001

Huffman GJ, Adler RF, Bolvin DT, Gu G (2009) Improving the global precipitation record: GPCP Version 2.1. Geophys Res Lett 36:L17808. https://doi.org/10.1029/2009GL040000

Hurrell JW, Hack JJ, Shea D, Caron JM, Rosinski J (2008) A new sea surface temperature and sea ice boundary dataset for the community atmosphere Model. J Clim 21:5145-5153

Josepth PV, Bindu G, Preeti B (2016) Impact of upper tropospheric cooling trend over central Asia on the Indian summer monsoon rainfall and the Bay of Bengal cyclone tracks. Curr Sci 110:2105-2113

Kim B-J, Moon S-E, Lu R, Kripalani RH (2002) Teleconnections: summer monsoon over Korea and India. Adv Atmos Sci 19:665-676. https://doi.org/10.1007/s00376-002-0006-z

Kripalani RH, Kulkarni A (1997) Climatic impact of El Niño/La Niña on the Indian monsoon: a new perspective. Weather 52(2):39-46

Kripalani RH, Kulkarni A (2001) Monsoon rainfall variations and teleconnections over South and East Asia. Int J Climatol 21:603-616

Kripalani RH, Singh SV (1993) Large scale aspects of India-China summer monsoon rainfall. Adv Atmos Sci 10:71-84. https://doi. org/10.1007/BF02656955

Kripalani RH, Kim B-J, Oh J-H, Moon S-E (2002) Relation between Soviet snow and Korean rainfall. Int J Climatol 22:1313-1325

Krishnamurti TN, Bhalme HN (1976) Oscillations of a monsoon system. Part 1. Observational aspects. J Atmos Sci 33:1937-1954

Krishnan R, Sugi M (2001) Baiu rainfall variability and associated monsoons teleconnections. J Meteorol Soc Jpn 79:851-860 
Lau K-M, Kim K-M, Yang S (2000) Dynamical and boundary forcing characteristics of regional components of the Asian summer monsoon. J Clim 13:2461-2482

Liu YY, Ding YH (2008) Analysis and numerical simulations of the teleconnection between Indian summer monsoon and precipitation in North China. Acta Meteorol Sin 66:789-799 (in Chinese with English abstract)

Lott F, Miller M (1997) A new sub-grid scale orographic drag parameterization: its formulation and testing. Q J R Meteorol Soc 123:101-128

Majewski D, Liermann D, Prohl P, Ritter B, Buchhold M, Hanisch T, Paul G, Wergen W, Baumgardner J (2002) The operational global icosahedral-hexagonal gridpoint model GME: description and high-resolution tests. Mon Weather Rev 130:319-338

Müller E (1981) Turbulent flux parameterization in a regional-scale model. ECMWF Workshop on planetary boundary layer parameterization, pp 193-220

Preethi B, Mujumdar M, Kripalani RH, Prabhu A, Krishnan R (2017a) Recent trends and tele-connections among South and East Asian summer monsoons in a warming environment. Clim Dyn 48:2489-2505

Preethi B, Mujumdar M, Prabhu A, Kripalani RH (2017b) Variability and teleconnections of South and East Asian Summer Monsoons in present and future projections of CMIP5 climate models. Asia Pac J Atmos Sci 53:305-325

Ramage CS (1971) Monsoon meteorology. International geophysical series, vol 15. Academic Press, London, p 296

Ritter B, Geleyn JF (1992) A comprehensive radiation scheme for numerical weather prediction models with potential applications in climate simulations. Mon Weather Rev 120:303-325

Sarthi PP, Dash SK, Mamgain A (2012) Possible changes in the characteristics of Indian summer monsoon under warmer climate. Glob Planet Chang 92:17-29

Scoccimarro E, Gualdi S, Bellucci A, Sanna A, Fogli PG, Manzini E, Vichi M, Oddo P, Navarra A (2011) Effects of tropical cyclones on ocean heat transport in a high resolution coupled general circulation model. J Clim 24:4368-4384

Tao SY, Chen LX (1987) A review of recent research on the EASM in China. In: Chang CP (ed) Monsoon Meteorology. Oxford University Press, Oxford, pp 60-92

Taylor KE, Stouffer RJ, Meehl GA (2012) Overview of CMIP5 and the experiment design. Bull Am Meteorol Soc 93:485-498

Tiedtke M (1989) A comprehensive mass flux scheme for cumulus parameterization in large-scale models. Mon Weather Rev 117:1779-1800

Wang B (2006) The Asian monsoon. Praxis Publishing, Chichester, p 787

Wang B, Wu R, Lau K-M (2001) Interannual variability of Asian summer monsoon: contrast between the Indian and western North Pacific-East Asian monsoons. J Clim 14:4073-4090

Wu R (2017) Relationship between Indian and East Asian summer rainfall variations. Adv Atmos Sci 34:4-15

Wu R, Wang B (2002) A contrast of the East Asian summer monsoon-ENSO relationship between 1962-77 and 1978-93. J Clim 15:3266-3279

Xie P, Arkin PA (1997) Global precipitation: a 17-year monthly analysis based on gauge observations, satellite estimates, and numerical model outputs. Bull Am Meteorol Soc 78:2539-2558

Yasunari T (1980) A quasi-stationary appearance of the 30-40 day period in the cloudiness fluctuations during the summer monsoon over India. J Meteorol Soc Jpn 58:225-229 (in Japanese)

Yun K-S, Lee J-Y, Ha K-J (2014) Recent intensification of the South and East Asian monsoon contrast associated with an increase in the zonal tropical SST gradient. J Geophys Res Atmos 119:8104-8116

Zhang R (2001) Relations of water vapor transport from Indian monsoon with that over East Asia and the summer rainfall in China. Adv Atmos Sci 18:1005-1017 